\title{
WHAT'S YOUR PHONE NUMBER? A VERY VERY SHORT SCREENING TEST FOR DEMENTIA
}

\author{
R. Correia ${ }^{1}$ \\ 1- Centro Hospitalar Universitário do Algarve, Departamento de Psiquiatria e Saúde Mental, Faro, Portugal. \\ saraivacorreia@gmail.com
}

\section{OBJECTIVES:}

Presentation of the "Phone Number Test" a very short screening test for dementia in a community outpatient clinic.

\section{BACKGROUND:}

The assessment of cognitive function in old age is a great challenge in the clinical practice. The increasing number of patients with dementia justifies a growing need for accurate and valid cognitive assessment instruments. There is an urgent need to make screening processes for dementia easier, less time-consuming and sensitive so that it can be used by all healthcare professionals.

\section{METHODOLOGY:}

To evaluate the "Phone Number Test" a transversal study was conducted in 2 groups of participants in a community outpatient clinic.

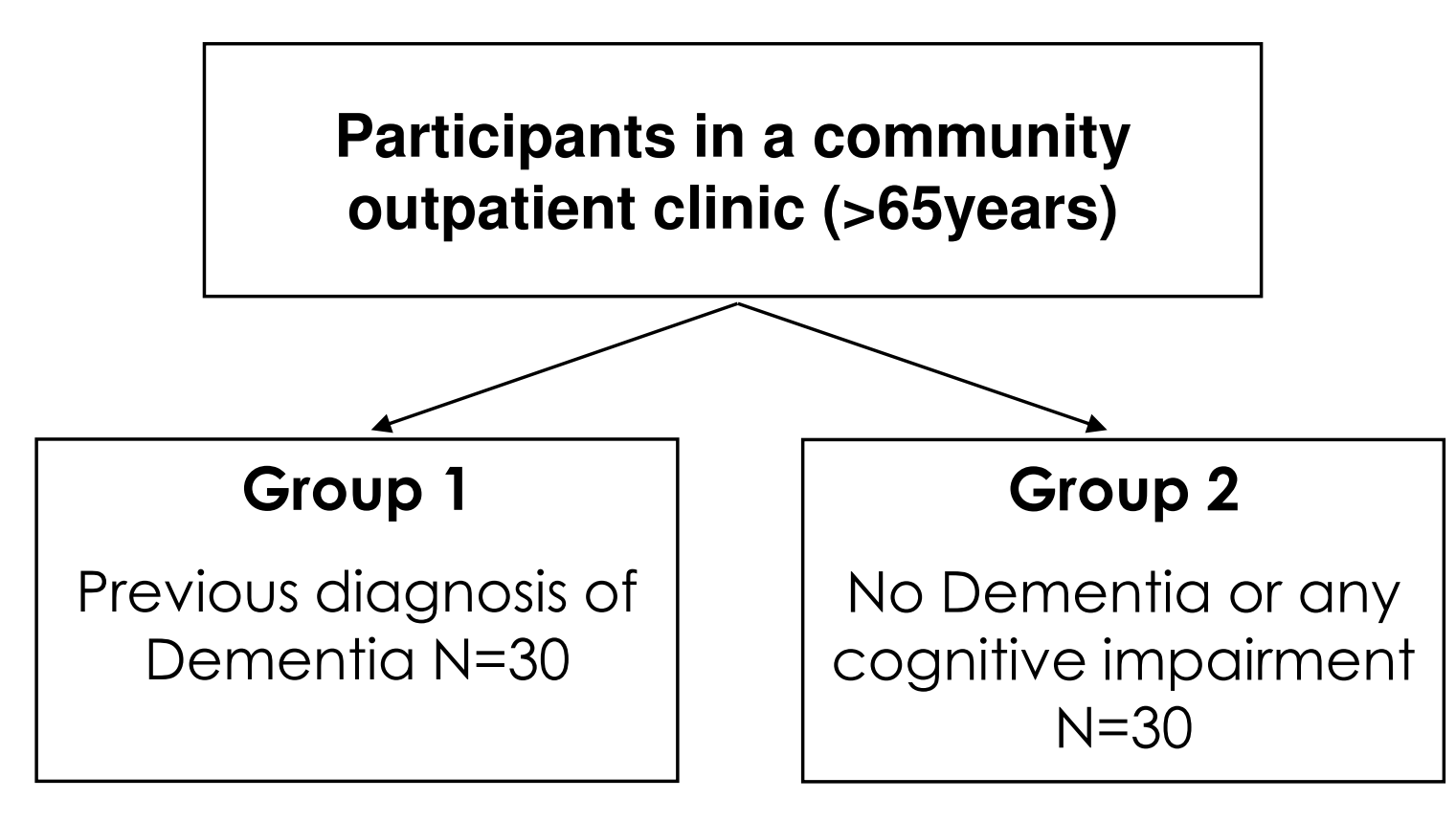

Demographic data, including age and gender and sociocultural status, has collected for all patients.

\section{THE TEST:}

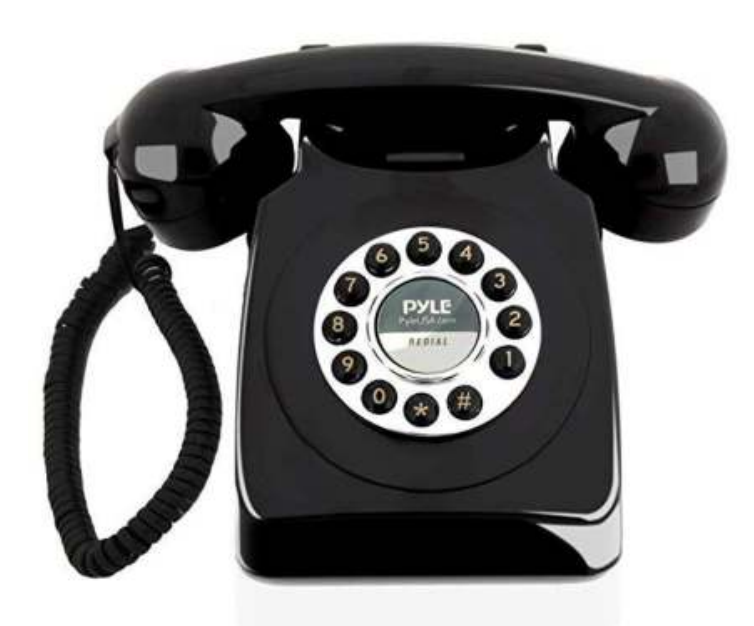

The "Phone Number Test" consists in inquiring the personal phone number of the patient during the clinical interview.

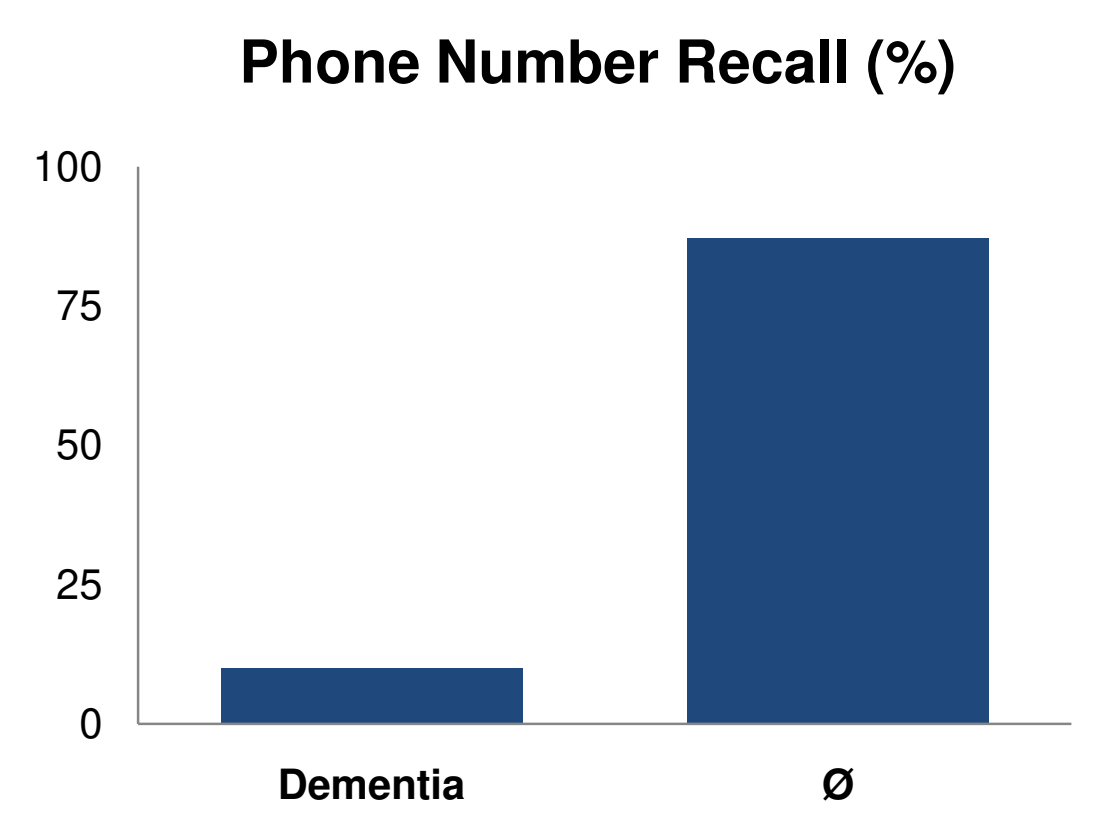

\section{CONCLUSIONS:}

The noticeable inability of the patients with dementia of recall their personal phone number when assessed with the "Phone Number Test" versus the group of patients without dementia or other cognitive impairment, with similar demographic and sociocultural characteristics in this pilot study, suggests that the "Phone Number Test" can be an alternative cognitive assessment instrument in the screening of dementia, providing a fast and promising approach. The instrument still need refinement in the validation steps, including comparison with other single instruments or neurocognitive test batteries. 